\title{
Exosomal therapy-a new frontier in regenerative medicine
}

\author{
Sathish Muthu ${ }^{1,2,3}$, Asawari Bapat ${ }^{4} \wedge$, Rashmi Jain ${ }^{3,5}$, Naveen Jeyaraman ${ }^{3,6}$, Madhan Jeyaraman ${ }^{2,3,7}$ \\ ${ }^{1}$ Department of Orthopaedics, Government Hospital, Velayuthampalayam, Karur, Tamil Nadu, India; ${ }^{2}$ Department of Biotechnology, School of \\ Engineering and Technology, Sharda University, Greater Noida, Uttar Pradesh, India; ${ }^{3}$ Indian Stem Cell Study Group (ISCSG), Lucknow, Uttar \\ Pradesh, India; ${ }^{4}$ Director of Quality and Regulatory Affairs, Infohealth FZE, Dubai, United Arab Emirates; ${ }^{5}$ School of Medical Sciences and Research, \\ Sharda University, Greater Noida, Uttar Pradesh, India; ${ }^{6}$ Department of Orthopaedics, Kasturba Medical College, MAHE University, Manipal, \\ Karnataka, India; ${ }^{7}$ Department of Orthopaedics, School of Medical Sciences and Research, Sharda University, Greater Noida, Uttar Pradesh, India \\ Contributions: (I) Conception and design: A Bapat; (II) Administrative support: N Jeyaraman; (III) Provision of study materials or patients: M \\ Jeyaraman, S Muthu; (IV) Collection and assembly of data: M Jeyaraman, S Muthu; (V) Data analysis and interpretation: R Jain; (VI) Manuscript \\ writing: All authors; (VII) Final approval of manuscript: All authors. \\ Correspondence to: Dr. Madhan Jeyaraman. Department of Orthopaedics, School of Medical Sciences and Research, Sharda University, Greater Noida, \\ Uttar Pradesh, India. Email: madhanjeyaraman@gmail.com.
}

\begin{abstract}
The recent advances in translational and nanomedicine have paved the way for developing the targeted drug delivery system at a greater pace among global researchers. On par with these technologies, exosomes act as a potential portal for cell-free drug delivery systems as these are bestowed with the native characteristics of the parent cell of origin. Exosomes, called extracellular vesicles (EcVs), are present in almost all cells, tissues, and body fluids. They help in intercellular signaling and maintains tissue homeostasis in the disease pathobiology. Researchers have characterized 9,769 proteins, 2,838 miRNAs, 3,408 mRNAs, and 1,116 lipids being present in exosomal cargo. The separation of exosomes from cells, tissues, and body fluids follow different patterned kinetics. Exosomes interact with the recipient cells through their surface receptor molecules and ligands and internalize within recipient cells through micropinocytosis and phagocytosis. Advancing technologies in regenerative medicine have facilitated the researchers to isolate exosomes from mesenchymal stem cells (MSCs) as these cells are blessed with supreme regenerative potentiality in targeting a disease. Exosomal cargo is a key player in establishing the diagnosis and executing therapeutic role whilst regulating a disease process. Various in vitro studies have exhibited the safety, efficacy, and therapeutic potentiality of exosomes in various cancers, neurodegenerative, cardiovascular, and orthopedic diseases. This article throws light on the composition, therapeutic role, and regulatory potentials of exosomes with the widening of the horizon in the field of regenerative medicine.
\end{abstract}

Keywords: Exosomes; extracellular vesicles (EcVs); cellular therapy; biological medicine

Received: 03 August 2020; Accepted: 16 March 2021; Published: 02 April 2021.

doi: $10.21037 /$ sci-2020-037

View this article at: http://dx.doi.org/10.21037/sci-2020-037

\section{Introduction}

The contemporary developments in the field of translational medicine include the development of targeted drug delivery systems for harnessing the full potentiality and utilizing the therapeutic products effectively by overcoming the limitations of the existing methods to address the pathogenesis of a disease. In that context, various polymerbased nano delivery systems have been developed (1). Utilizing extracellular vesicles (EcVs) as a drug delivery

^ ORCID: Sathish Muthu, 0000-0002-7143-4354; Asawari Bapat, 0000-0002-4592-7702; Rashmi Jain, 0000-0003-4386-6755; Naveen Jeyaraman, 0000-0002-4362-3326; Madhan Jeyaraman, 0000-0002-9045-9493. 
tool has been given special attention due to their naïve characteristics derived from the parent or host cells (2-4). Despite the normal cellular homeostasis, EcVs play a major role in intervening in the pathobiology of disease processes through the intercellular signaling cascade (5-9).

Based on the size, exosomes are subcategorized under $\mathrm{EcVs}$, which are endosome derived lipid bi-layered spherical vesicles of $40-150 \mathrm{~nm}$ in size $(2,10-12)$. Almost all cells, tissues, and body fluids [plasma, urine, saliva, tears, gastrointestinal (GI) secretions, semen, and breast milk] secrete exosomes (13-16). Exosomal cargo carries an array of micro-biomolecules that consists of proteins, lipids, RNA, and DNA from the secreting parent cells (2,17-19). Moreover, the characteristics and behavior of the exosomes closely relate to the parent cell of origin (20-22). On account of their appropriate size and property along with their evident role in numerous pathobiological processes, the potential of exosomal therapy in the management of various neurodegenerative disorders, infectious diseases, musculoskeletal disorders, and cardiovascular disorders is overwhelming. This has enabled the researchers to target the disease process at a cellular level by using natural engineered defense mechanisms.

\section{Characterization of exosomes}

The composition of an exosome vesicle (EV) includes proteins, RNA, DNA, and other substances. Currently, 9,769 proteins, 2,838 miRNAs, 3,408 mRNAs, and 1,116 lipids have been described in their composition (23). Of these components, the exosomal proteins differ based on the nature of the primitive cells or tissues (24). Proteins like membrane transport and fusion proteins, chaperones, adhesion molecules, MHCs, cytoskeletal proteins, and lipid-related proteins are major exosomal proteins (24-28). With a pre-existing knowledge of the functioning of these proteins, ALG-2-interacting protein X (ALIX), heat shock protein 70 (HSP 70), tumor susceptibility gene 101 (TSG101), and tetraspanins (CD9, CD 63, CD 81, and CD 82) have been identified with a higher concentration in exosomes (29,30). Moreover, they serve as a biomarker for exosomal identification as shown in Figure 1 (31). Exosomes are also rich in lipid layering molecules like glycosylphosphatidylinositol-anchored protein (LBPA) and flotillin $(32,33)$. Apart from the metabolic enzymes and signal transduction molecules such as $G$ protein and protein kinases, exosomes contain mRNAs, miRNAs, non-coding RNAs (ncRNAs), and mitochondrial DNA in their composition $(34,35)$. Noteworthy, the first types of nucleic acids identified in the exosomes were mRNA and miRNA (36,37).

Being a nanoscale vesicular component in complex body fluids, it is challenging to procure exosomes of highyield and fineness (38). However, their isolation and characterization is an essential prerequisite to establish their therapeutic potential with a better understanding of their physiology. Exosomes are derived from the cell culture supernatants or plasma with their identification based on the physical and morphological characteristics $(39,40)$. Although separation can be made by several methods like ultracentrifugation, ultrafiltration, gradient ultracentrifugation, precipitation, size-exclusion chromatography, immuneaffinity capture, mass spectrometric immunoassay, magneticactivated cell sorting, and microfluidics-based techniques with each having their advantages and disadvantages (41-45) Ultracentrifugation is the most commonly used method for isolating exosomes. The complex proteins in the exosomes are analyzed by processes like western blot, flow cytometry, and mass spectrometry (46). Additionally, sample analysis with high precision fluorescence is a possibility in the nanoparticle tracking method (47). Homogeneity without exosome isolation is possible with the resistance pulse sensing method (48). Profiling the miRNA content of the exosomes was made with next-generation sequencing, microarray processing, and RT-PCR. Confirmation of the isolated samples can be done by electron microscopy (49). Disparate use of various methods of isolation, confirmation, quantification, and analysis used by the researchers with their own set of advantages and disadvantages, it brings added heterogeneity in their analysis which needs standardization.

\section{Cellular physiology of exosomes}

The formation of exosomes involves the invagination of the plasma membrane and the formation of intracellular multivesicular bodies with intraluminal vesicles. This endocytic pathway of the donor cell is followed by the transport of the transmembrane and intra-vesicular proteins from the Golgi complex resulting in the formation of early endosomes. After maturation and differentiation, they get transformed into late endosomes (50-53). They are degraded by fusing with lysosomes or plasma membrane or autophagosomes to release the intraluminal vesicles as exosomes (measuring $40-150 \mathrm{~nm}$ diameter) into the extracellular milieu as shown in Figure 2 $(5,32,54)$. 


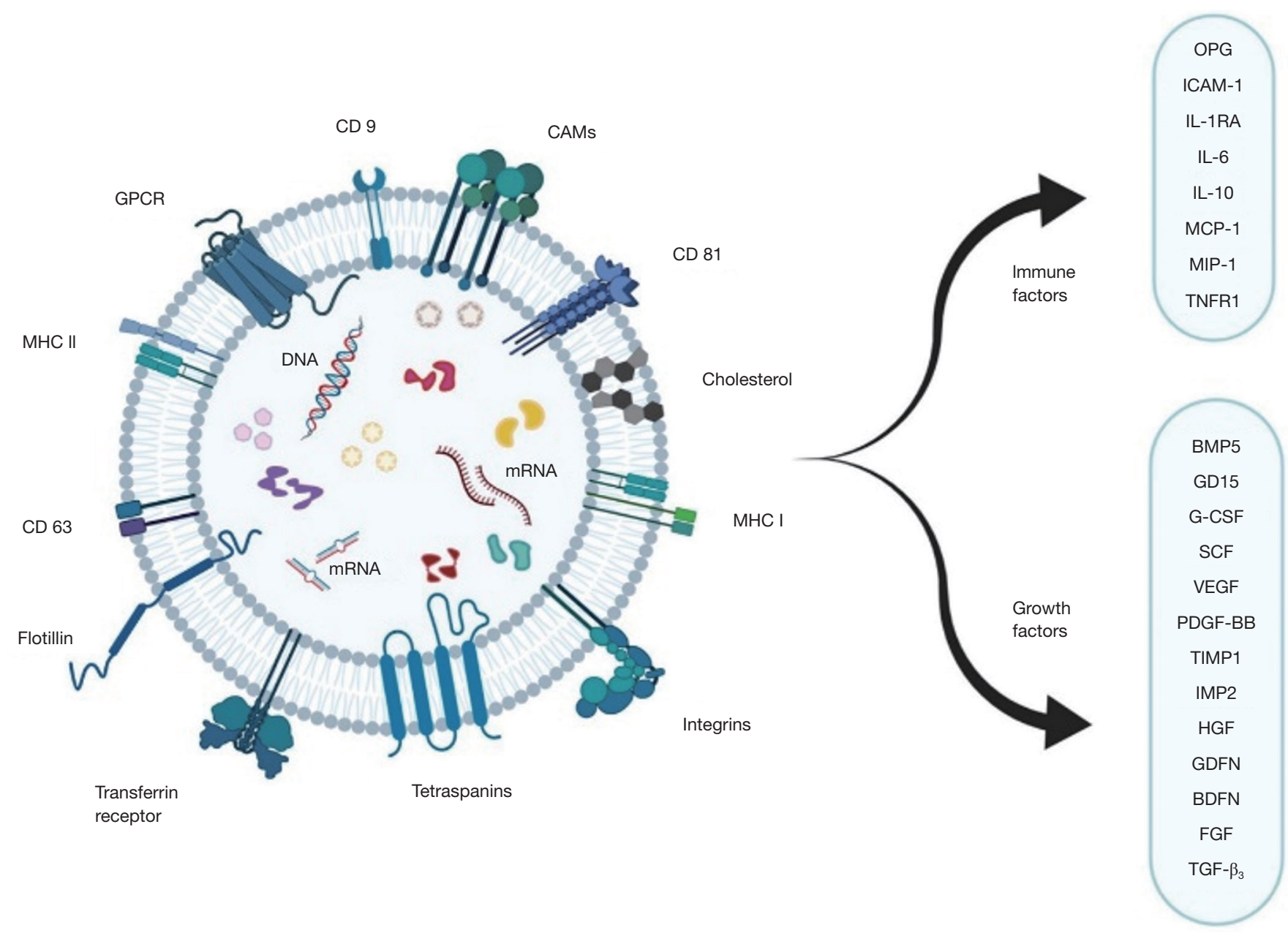

Figure 1 Basic structure of mesenchymal stem cell exosome depicting the surface and core proteins along with the key immune and growth factors.

Exosomes interact with the recipient cells through their surface receptor molecules and ligands. Some of the exosomes persist on the cell membranes of the donor cells after secretion while the rest of them interacts with the recipient cells (54-59). Internalization of exosomes occurs via membrane integration process mediated by raft or caveolae or clathrin dependent endocytosis. Micropinocytosis and phagocytosis have also been described as a method of internalization of the exosomes by recipient cells. This physiological integration process on the targeted recipient cells has been considered to have therapeutic potential as a targeted delivery system for effectively executing biological functions (60-64). Yet, the exosomal components in specific accounting for cell-type or organ specificity remain unclear (65).

\section{Diagnostic role of exosomes}

Exosomes are the key players of the intercellular communication portal and thereby owe the capability of determining the progression of a disease. Studies are emerging in the diagnostic and therapeutic facets of exosomes for various systemic pathologies. The detection of substances (intracellular and extracellular) carried by these nanoparticles and promoting their immune capture with surface proteins aid in the diagnosis of pathological processes. The spectrum of diseases in which exosomes play a key role in diagnosis includes cerebrovascular disease $(66,67)$, diseases involving the central nervous system and neoplasm $(8,68-70)$ along with disease involving kidney, liver, and lungs (70-72). Let us consider the scenario of cancer. Exosomes can protect the rapid degradation of 


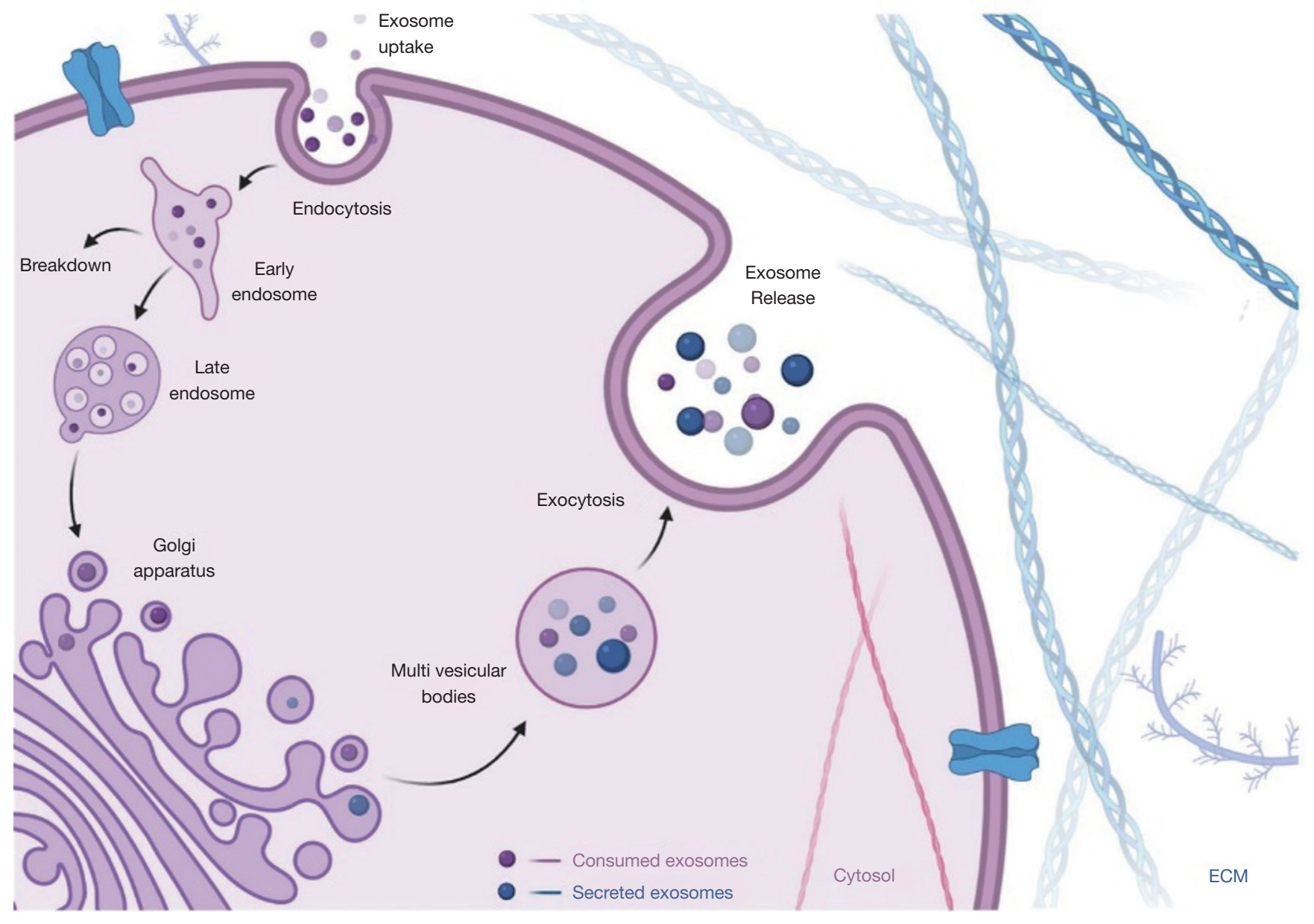

Figure 2 Physiology of formation and degradation of exosomes. ECM, extracellular matrix.

nucleic acids and remain highly stable in plasma (73). With an exosome-based liquid biopsy, direct detection of the circulating tumor cells and their DNA or cell-free RNA from body fluids like blood, saliva can be made. This DNA or RNA (including mRNA, miRNA, ncRNA) from serum exosomes can be used for the detection of cancerrelated mutations making them a promising biomarker in cancer diagnosis (74-77). Various studies have identified proteins and RNAs rich in cancer-derived exosomes which act as biomarkers that can be used in the detection and prognosticating treatment response (78-85).

\section{Therapeutic role of exosomes}

Exosomes possess a higher therapeutic potential for various disease spectra due to their ability for intracellular shuttling. Nanomedicine technologies have given rise to explore the usage of pathogenic importance of exosomal particles in various diseases. The targeted drug delivery system in nanomedicine focus on the sustained release of exosomes for exerting the biological activity in the targeted site. Exosomes are used as vectors or carrier molecules to elicit a biological response.

Under given physiological circumstances, exosomes demonstrate very low immunogenicity and the potential to circumvent the physiological blood-brain-barrier (86). With the help of a stable lipid bilayer, the cargoes loaded in the exosomal vesicles are guarded against the action of native immune cells and digestive enzymes. The engineered exosomal vesicles deliver the cargoes loaded to them to the site of action through various mechanisms of endocytosis or membrane fusion as shown in Figures 3 and $4(87,88)$. EVs are derived from various cell types and tissues. On delivery to specific diseased tissue, under specific conditions, EV elicits 
Exosome uptake mechanisms

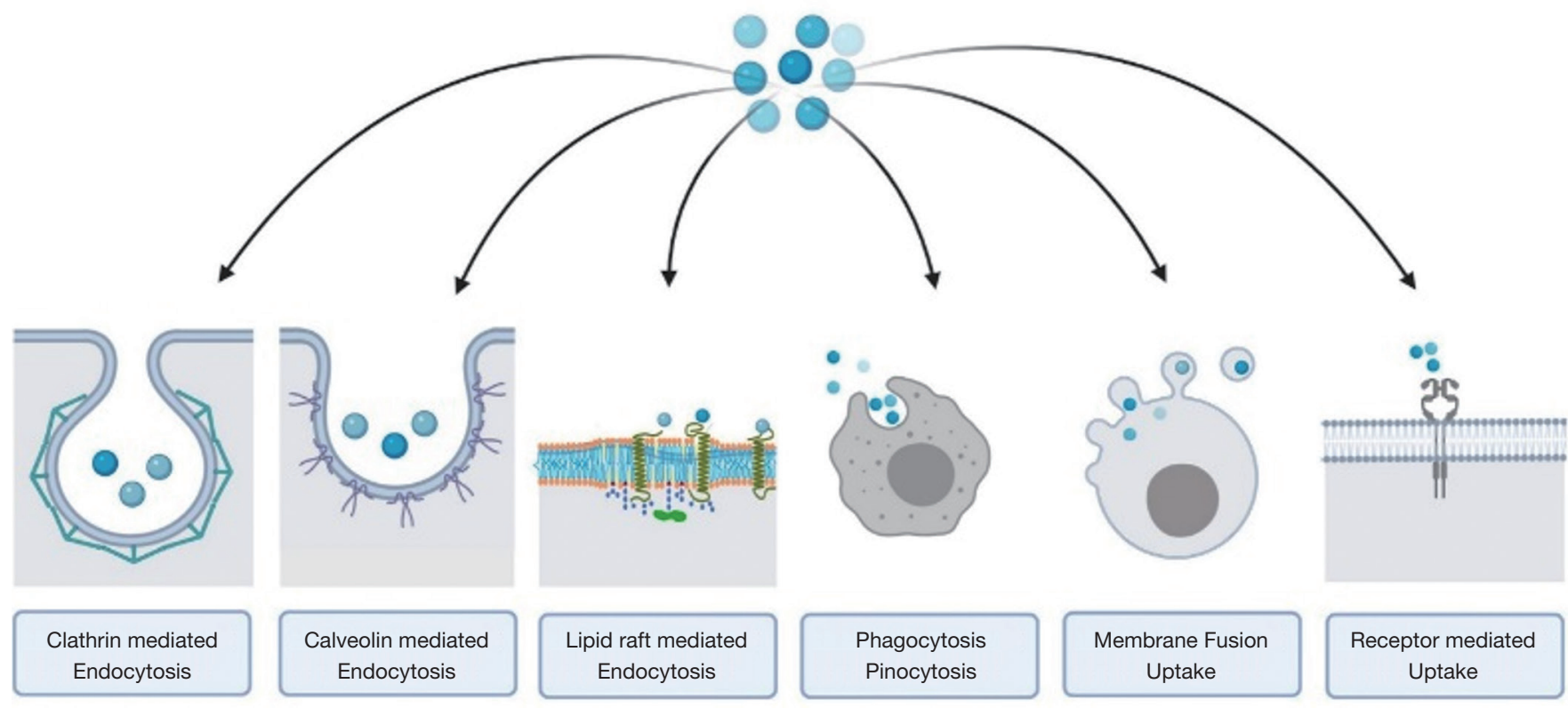

Figure 3 Methods of uptake of exosomes by the target cells.

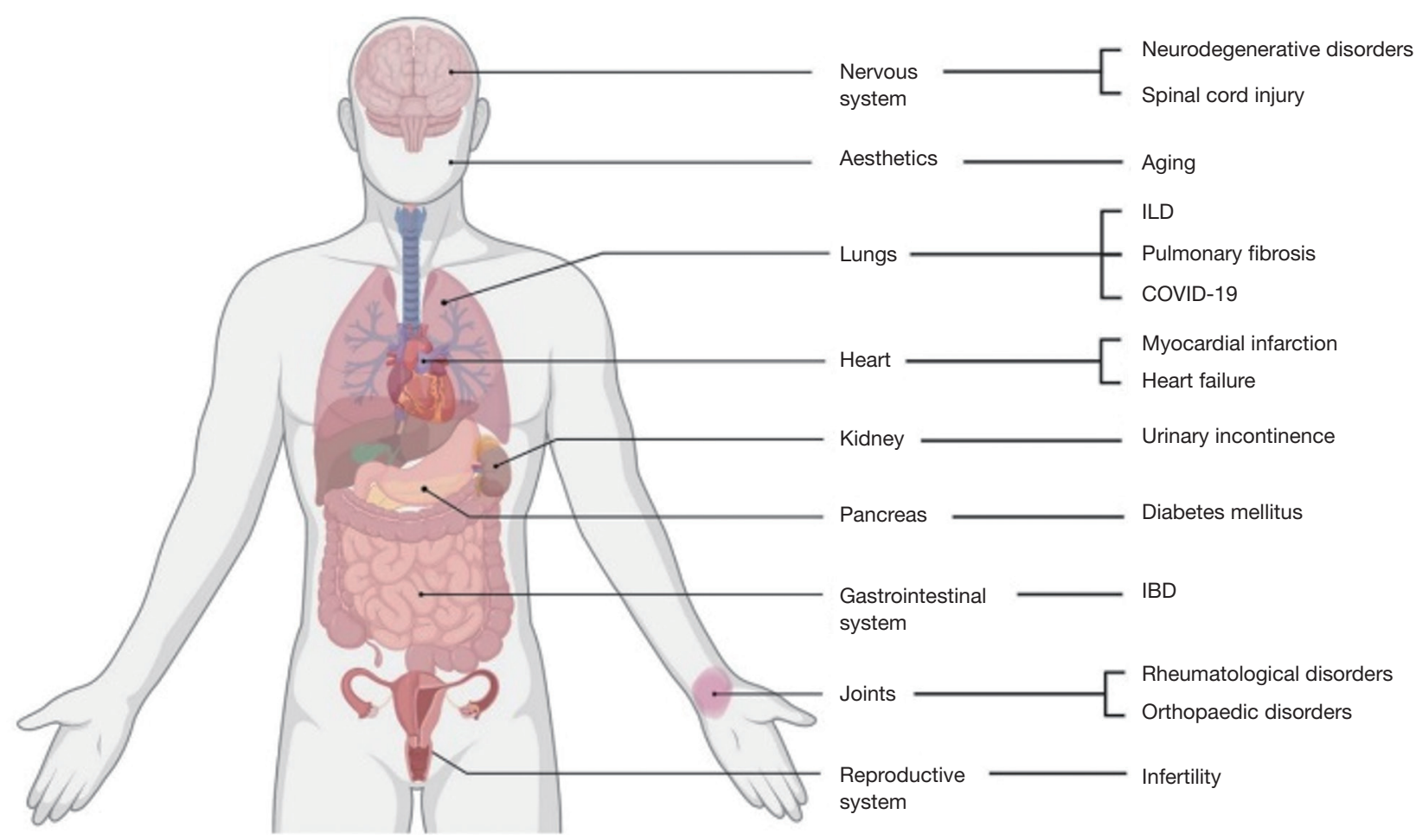

Figure 4 Potential therapeutic applications of exosomes. ILD, interstitial lung disease; IBD, inflammatory bowel disease. 
tissue regeneration and homeostasis (89). Mesenchymal stromal cell-derived EV show cellular viability, trophicity, anti-inflammatory, immunomodulatory and therapeutic effects $(90,91)$. They support neoangiogenesis and cellular proliferation (2,92-95). Exosomes demonstrate the homing effect of the parental cell type $(2,96)$.

The superiority of the exosomal cargos compared to the stem cells on clinical and therapeutic potential is noted by

(I) Lack of inherent risk associated with any cell-based therapies including stem cells;

(II) Lack of replicating potential and the risk of malignant transformation;

(III) Lack of immunogenic response towards infections and cancers;

(IV) Targeted action at the site of interest $(2,97)$.

The above-mentioned versatility of EVs enhances their intracellular signaling capabilities and their movement across cellular membranes to restore micromolecular homeostasis. Apart from these advantages, exosomes also offer neuroprotection and neuroplasticity by shuttling across the blood-brain barrier in neurodegenerative diseases (98). A total of 77 clinical trials have been registered among the global researchers in various pathologies. Out of 77 trials, 11 clinical trials have been completed and have proved the positive diagnostic and therapeutic effects of exosomebased treatment in various cancers, neurodegenerative and hematological diseases (99).

\section{Sources of isolation of exosomes}

The exosomes are also called intraluminal vesicles and are found in various tissues and body fluids (5-7). The exosomes derived from mesenchymal stem cells (MSCs) are of prime importance due to the greater therapeutic and regenerative potential as shown in Figure 4. Due to the challenges faced in isolating exosomes from various body fluids, regenerative and translational medicine experts used MSC-derived exosomes for treating various disorders (2). MSCs derived exosomal cargo exhibit intracellular signaling and communications to targeted tissues. The key sources of exosomes derived from the MSCs include bone marrow, adipose tissue, placental cells, umbilical cells, endometrial fluid, and amniotic fluid $(2,100)$.

Exosomes of MSC origin have cell surface markers such as CD 29, CD 44, and CD 73 embedded in them (100). They play a vital role in the biomechanisms involved in the repair and regeneration, bioenergetics, immunoregulation, intracellular communication, and tissue metabolism $(2,101)$.
In a proteomic analysis, a total of 730 protein molecules in bone marrow MSC derived exosomes were isolated (102). Some researchers found the existence of transcription signaling factors in exosomal cargoes (103). Amniotic fluid exosomes are the most preferred exosomes for clinical applications than bone marrow-derived exosomes (104).

\section{Routes of delivery of exosomes}

The different state of the art approaches to deliver the exosomes to their site of action and their shortcomings were analyzed and presented with their challenges encountered in them. The most common route is intravenous (IV) despite its clearance in the liver and the kidney is rapid in this method (105). This method was widely used for conditions involving orthopedic, neoplastic, and cardiovascular pathologies (106). Intramuscular (IM) has been primarily used in neuromuscular and musculoskeletal conditions while subcutaneous (SC) route in aesthetic and cosmetic indications. The IM or SC route is chosen due to the ease of injectable area and the dosing volume (97). Intrathecal is the preferred route in neurodegenerative conditions such as Alzheimer's, Parkinson's, and Creutz-Feld Jakob's disease $(98,99)$. Local aerosol sprays are used in the management of wounds and ulcers $(107,108)$. For hair growth and rejuvenation in age-related therapies, this is the preferred route $(108,109)$. During the time of the coronavirus disease-2019 (COVID-19) pandemic, there have been interesting studies discussing the role of exosomal therapy as a promising therapeutic candidate (110).

\section{Global regulatory requirements}

With the growing therapeutic spectrum of exosomal therapy, the International Society for Extracellular Vesicles (ISEV) and the European Network on Microvesicles and Exosomes in Health and Disease (ME-HaD) have formulated certain guidelines to foster their clinical usage (10). The regulations elaborate on the standard operative protocols to be followed in the process of collection, processing, testing, quality control, and manufacturing of exosomes for clinical usage. With the help of these policies, the potential of the EVs can be utilized at appropriate standards for therapeutic usage.

Any novel therapy or a drug being developed is dependent on the strategies to standardize the process to focus on validating the proposed technology. There are currently no Food and Drug Administration (FDA)- 
approved exosome products for human use in the USA $(2,111)$. According to the FDA, exosomes are classified as a 351 product that requires studies effectively showing safety and efficacy, along with the purity of the product and its potency in treating the condition (112). Therapies using the exosomes are under the Investigational New Drug (IND) developmental phase and need the approval of the regulatory agencies before initiating the clinical trial $(2,113)$.

The regulatory framework addresses the safety standards for microbial and viral contamination and demands $\mathrm{GxP}$ standards $(\mathrm{GxP}=$ good manufacturing/good laboratory/ good distribution/good clinical/good scientific practice or GMP/GLP/GDP/GCP/GSP) for the production and quality control of the corresponding therapeutics $(114,115)$. It regulates the conduct of clinical trials (116). There remains an issue with the categorization of any emerging novel therapeutics for humans.

\section{Pharmaceutical category of EV preparations}

According to the Center for Biologics Evaluation and Research (CBER), the exosomes are regulated as biological products $(117,118)$. Based on the individual types, the framework that was laid down for products in this category applies to the exosomes. For example, an anti-tumor vaccine that uses exosomes will be regulated under the regulations provided for therapeutic cancer vaccines (119). The functional moiety in EV-based therapy determines its medicinal type $(2,120)$.

Hence, ISEV categorizes EV-based therapy under biological medicines with the following properties.

(I) The therapeutics acquired from unmodified cells.

(II) Therapeutics acquired from genetically manipulated cells (without trans-gene).

(III) Therapies acquired from exosomes and genemodified cells with trans-gene classified as gene therapy products (GTP).

(IV) Native exosomal therapies; are used as drugdelivery systems, used as carriers for the biological and chemical components, and are considered as biological medicine.

As the biological medicinal products include a span of various pharmaceuticals, these were classified as Advanced Therapy Medicinal Products (ATMP's) in 2007 (2,120). It was further subgrouped to conventional biological medicinal products due to the biological properties, physicochemical and immunochemical properties $(117,118)$. It includes somatic cell therapy, gene therapies, and tissue- engineered products.

ATMP's therapeutics involve products that have been:

(I) More than minimally manipulated such as cell expansions and cell cultures.

(II) Intended for non-homologous use. For example use of hematopoietic cells for orthopedics.

(III) Nucleated and viable cells are present in the product.

(IV) Products with therapeutically active trans-gene from genetically engineered cells are considered as ATMPs, independent of the presence of any nucleated, viable cell.

(V) EV-based therapeutics classified as ATMP's; are produced from human material by a manufacturing process comparable to the ATMP production.

\section{Safety profile, manufacturing \& standardization}

The mechanism of action (MoA) is essential for the clinical translation of therapeutics based on EVs (121). The critical part of this translation is the identification of "active substances", their properties, and the essential quality controls in manufacturing a clinical-grade product (118). For phase I the hypothesis should be based on the proof of principle, reinstate the rationale based on the MoAs. Although uncertainties exist on the MoA of EV-based therapeutics on the target cells, with supportive animal models, EVs from human cells are not to be accounted as high risk in an IND (116). Commercializing a large scale manufacturing of $\mathrm{EV}$ based therapeutics requires a robust quality management system, technologically superior facility, and an updated technology complying with $\mathrm{GxP}$ $(114,115)$. The endpoint of these investigational studies is to provide safety for the donor and the patient. The criteria for the therapeutic release of an investigational product is to determine efficacy based on the pre-IND studies for characterization (116).

At this moment the EV's do not have a standardized protocol for isolation and storage; and include homemade cocktails as protocols with no standardization for reagents, storage containers, and storage time for each desired EVbased product $(2,10,122)$.

\section{Direction for future research}

The scope of exosomal therapy among various other clinical fields remains untouched. With the global interest of the researchers towards harnessing the potential of 
Table 1 Companies targeting on exosomal research and their potential products for commercial use

\begin{tabular}{|c|c|c|c|}
\hline Company & Exosomal source & Exosomal product & Exosomal potential \\
\hline Exosomedx (130) & $\begin{array}{l}\text { Plasma or serum- } \\
\text { derived exosomes }\end{array}$ & ExoDx & CLIA certified product to conduct advanced clinical testing \\
\hline NanoSomiX (131) & $\begin{array}{l}\text { Brain-derived exosomes } \\
\text { (BDEs) }\end{array}$ & ExoM and ExoC & $\begin{array}{l}\text { Biomarkers for prediction of potential nervous system } \\
\text { disorders }\end{array}$ \\
\hline Evox Therapeutics (132) & & & $\begin{array}{l}\text { For rare metabolic and lysosomal storage diseases } \\
\text { engaging endogenous and exogenous drug loading }\end{array}$ \\
\hline Codiak Biosciences (133) & $\begin{array}{l}\text { Engineered therapeutic } \\
\text { exosomes }\end{array}$ & & $\begin{array}{l}\text { Encompasses therapeutics for vaccines, anti-infectives, } \\
\text { oncology, autoimmune and anti-inflammatory diseases }\end{array}$ \\
\hline
\end{tabular}

MSC, mesenchymal stem cell; CLIA, Clinical Laboratory Improvement Amendments.

the exosomes, making EV based therapeutics a reality is not far from reach (10). The potential of EV based therapy is established in various orthopedic conditions, neurodegenerative disorders, auto-immune diseases, cardiovascular diseases, infectious diseases, and diagnosis of rare diseases including cancers $(98,99,123)$. However, the current domain of research in EV based therapeutics involve developing diagnostic and therapeutic applications towards patient care.

From the level of the circulating pool of EVs, early diagnosis of a complex disease could be made by using them as biomarkers in blood (74-82). Utilising the paracrine signaling property of the MSC-derived exosomes, repair, and regeneration of organs could be achieved (87-95). For use in most orthopedic conditions exosomes are deemed anti-inflammatory concerning their immunomodulatory potential (123). Understanding the role of exosomes in the disease processes have enabled us to propel our understanding of the disease and expand the scope of the therapies evolved out of them (124). As of now therapeutic applications of the EV-based therapies from defined cell sources based on their immunomodulatory capabilities include inflammatory disorders, degenerative disorders, vehicles of drug-delivery, anti-tumor therapies, and pathogen vaccination tool (98-102). Immunomodulatin of exosomes may be exerted by either immune-activation or suppression. This novel platform with the above-mentioned diverse potentials holds promise to develop vaccines with prolonged immunogenicity against infectious diseases or cancer $(125,126)$.

There is a paradigm shift brought down by the continual breakthroughs in research exploring the potential of the exosomes that have resulted in the development of novel therapeutic options that are reshaping the landscape of the global market from time to time. Despite being started as a subject of academic interest, exosomal therapy has now been transformed into a potential platform with immense promise for future therapeutics (127). This sowed the seeds for start-ups into exosome platforms with their proprietary technologies. Some of them are elaborated in Table 1. These companies are using patented technologies to tap the potential of exosomes. For example, the company Capricor Therapeutics developed an exosomal therapeutic technology from cardiosphere-derived cells (CDCs) called CAP2003 which is in the preclinical testing phase to explore the anti-inflammatory, pro-angiogenic, antiapoptotic, and antifibrotic effects associated with their parent CDCs. Additionally, the company is evaluating the role of CDCexosomes for the treatment of trauma-related injuries and conditions (135).

\section{Conclusions}

Exosomes play a natural role by enacting as a vehicle for the transfer of biological substances between cells and thereby renders a broader prospect to serve as a channel 
for delivering drugs of therapeutic interest. However, the intricate composition and uncertain functioning are inquisitive facets warranting further exploration. In view of making the exosome-based therapy a reality, more accurate, faster, cheaper, standardized, specific, and easier methods of their separation and purification have to evolve along with concrete adducing on its safety, feasibility, pharmacokinetic and pharmacodynamic characteristics through large scale prospective research studies.

\section{Acknowledgments}

Funding: None.

\section{Footnote}

Conflicts of Interest: All authors have completed the ICMJE uniform disclosure form (available at http://dx.doi. org/10.21037/sci-2020-037). The authors have no conflicts of interest to declare.

Etbical Statement: The authors are accountable for all aspects of the work in ensuring that questions related to the accuracy or integrity of any part of the work are appropriately investigated and resolved.

Open Access Statement: This is an Open Access article distributed in accordance with the Creative Commons Attribution-NonCommercial-NoDerivs 4.0 International License (CC BY-NC-ND 4.0), which permits the noncommercial replication and distribution of the article with the strict proviso that no changes or edits are made and the original work is properly cited (including links to both the formal publication through the relevant DOI and the license). See: https://creativecommons.org/licenses/by-nc-nd/4.0/.

\section{References}

1. Wu D, Abezgauz L, Danino D, et al. Alternating polymer vesicles. Soft Matter 2008;4:1066-71.

2. Jeyaraman M, Muthu S, Gulati A, et al. Mesenchymal Stem Cell-Derived Exosomes: A Potential Therapeutic Avenue in Knee Osteoarthritis. Cartilage 2020. doi: 10.1177/1947603520962567.

3. Pata V, Dan N. The effect of chain length on protein solubilization in polymer-based vesicles (polymersomes). Biophys J 2003;85:2111-8.

4. Zhang XY, Zhang PY. Polymersomes in Nanomedicine -
A Review. Current Nanoscience 2016. doi:10.2174/157341 3712666161018144519.

5. Kalluri R, LeBleu VS. The biology, function, and biomedical applications of exosomes. Science 2020;367:eaau6977.

6. Pegtel DM, Gould SJ. Exosomes. Annu Rev Biochem 2019;88:487-514.

7. Becker A, Thakur BK, Weiss JM, et al. Extracellular Vesicles in Cancer: Cell-to-Cell Mediators of Metastasis. Cancer Cell 2016;30:836-48.

8. Kalluri R. The biology and function of exosomes in cancer. J Clin Invest 2016;126:1208-15.

9. Robbins PD, Morelli AE. Regulation of immune responses by extracellular vesicles. Nat Rev Immunol 2014;14:195-208.

10. Théry C, Witwer KW, Aikawa E, et al. Minimal information for studies of extracellular vesicles 2018 (MISEV2018): a position statement of the International Society for Extracellular Vesicles and update of the MISEV2014 guidelines. J Extracell Vesicles 2018;7:1535750.

11. Cocucci E, Meldolesi J. Ectosomes and exosomes: shedding the confusion between extracellular vesicles. Trends Cell Biol 2015;25:364-72.

12. O'Brien K, Breyne K, Ughetto S, et al. RNA delivery by extracellular vesicles in mammalian cells and its applications. Nat Rev Mol Cell Biol 2020;21:585-606.

13. Caby MP, Lankar D, Vincendeau-Scherrer C, et al. Exosomal-like vesicles are present in human blood plasma. Int Immunol 2005;17:879-87.

14. Pisitkun T, Shen RF, Knepper MA. Identification and proteomic profiling of exosomes in human urine. Proc Natl Acad Sci U S A 2004;101:13368-73.

15. Michael A, Bajracharya SD, Yuen PS, et al. Exosomes from human saliva as a source of microRNA biomarkers. Oral Dis 2010;16:34-8.

16. Admyre C, Johansson SM, Qazi KR, et al. Exosomes with immune modulatory features are present in human breast milk. J Immunol 2007;179:1969-78.

17. Mathivanan S, Ji H, Simpson RJ. Exosomes: extracellular organelles important in intercellular communication. J Proteomics 2010;73:1907-20.

18. Sokolova V, Ludwig AK, Hornung S, et al. Characterisation of exosomes derived from human cells by nanoparticle tracking analysis and scanning electron microscopy. Colloids Surf B Biointerfaces 2011;87:146-50.

19. Kalra H, Adda CG, Liem M, et al. Comparative proteomics evaluation of plasma exosome isolation techniques and 
assessment of the stability of exosomes in normal human blood plasma. Proteomics 2013;13:3354-64.

20. Théry C, Ostrowski M, Segura E. Membrane vesicles as conveyors of immune responses. Nat Rev Immunol 2009;9:581-93.

21. Daaboul GG, Gagni P, Benussi L, et al. Digital Detection of Exosomes by Interferometric Imaging. Sci Rep 2016;6:37246.

22. Pitt JM, Kroemer G, Zitvogel L. Extracellular vesicles: masters of intercellular communication and potential clinical interventions. J Clin Invest 2016;126:1139-43.

23. Mathivanan S, Fahner CJ, Reid GE, et al. ExoCarta 2012: database of exosomal proteins, RNA and lipids. Nucleic Acids Res 2012;40:D1241-D1244.

24. Mathivanan S, Lim JW, Tauro BJ, et al. Proteomics analysis of A33 immunoaffinity-purified exosomes released from the human colon tumor cell line LIM1215 reveals a tissue-specific protein signature. Mol Cell Proteomics 2010;9:197-208.

25. Conde-Vancells J, Rodriguez-Suarez E, Embade N, et al. Characterization and comprehensive proteome profiling of exosomes secreted by hepatocytes. J Proteome Res 2008;7:5157-66.

26. Poliakov A, Spilman M, Dokland T, et al. Structural heterogeneity and protein composition of exosomelike vesicles (prostasomes) in human semen. Prostate 2009;69:159-67.

27. Simons M, Raposo G. Exosomes--vesicular carriers for intercellular communication. Curr Opin Cell Biol 2009;21:575-81.

28. Subra C, Grand D, Laulagnier K, et al. Exosomes account for vesicle-mediated transcellular transport of activatable phospholipases and prostaglandins. J Lipid Res 2010;51:2105-20.

29. Vlassov AV, Magdaleno S, Setterquist R, et al. Exosomes: current knowledge of their composition, biological functions, and diagnostic and therapeutic potentials. Biochim Biophys Acta 2012;1820:940-8.

30. Xie F, Zhou X, Fang M, et al. Extracellular Vesicles in Cancer Immune Microenvironment and Cancer Immunotherapy. Adv Sci (Weinh) 2019;6:1901779.

31. Jeppesen DK, Fenix AM, Franklin JL, et al. Reassessment of Exosome Composition. Cell 2019;177:428-445.e18.

32. van Niel G, D'Angelo G, Raposo G. Shedding light on the cell biology of extracellular vesicles. Nat Rev Mol Cell Biol 2018;19:213-28.

33. Valadi H, Ekström K, Bossios A, et al. Exosome-mediated transfer of mRNAs and microRNAs is a novel mechanism of genetic exchange between cells. Nat Cell Biol 2007;9:654-9.

34. Guescini M, Genedani S, Stocchi V, et al. Astrocytes and Glioblastoma cells release exosomes carrying mtDNA. J Neural Transm (Vienna) 2010;117:1-4.

35. Soung YH, Ford S, Zhang V, et al. Exosomes in Cancer Diagnostics. Cancers (Basel) 2017;9:8.

36. Ratajczak J, Miekus K, Kucia M, et al. Embryonic stem cell-derived microvesicles reprogram hematopoietic progenitors: evidence for horizontal transfer of mRNA and protein delivery. Leukemia 2006;20:847-56.

37. Turchinovich A, Weiz L, Langheinz A, et al. Characterization of extracellular circulating microRNA. Nucleic Acids Res 2011;39:7223-33.

38. Willms E, Cabañas C, Mäger I, et al. Extracellular Vesicle Heterogeneity: Subpopulations, Isolation Techniques, and Diverse Functions in Cancer Progression. Front Immunol 2018;9:738.

39. Bard MP, Hegmans JP, Hemmes A, et al. Proteomic analysis of exosomes isolated from human malignant pleural effusions. Am J Respir Cell Mol Biol 2004;31:114-21.

40. Navabi H, Croston D, Hobot J, et al. Preparation of human ovarian cancer ascites-derived exosomes for a clinical trial. Blood Cells Mol Dis 2005;35:149-52.

41. Li P, Kaslan M, Lee SH, et al. Progress in Exosome Isolation Techniques. Theranostics 2017;7:789-804.

42. Momen-Heravi F, Balaj L, Alian S, et al. Current methods for the isolation of extracellular vesicles. Biol Chem 2013;394:1253-62.

43. Théry C, Amigorena S, Raposo G, et al. Isolation and characterization of exosomes from cell culture supernatants and biological fluids. Curr Protoc Cell Biol 2006; Chapter 3:Unit 3.22. doi: 10.1002/0471143030.cb0322s30.

44. $\mathrm{Xu} \mathrm{R}$, Greening DW, Zhu HJ, et al. Extracellular vesicle isolation and characterization: toward clinical application. J Clin Invest 2016;126:1152-62.

45. Gulei D, Irimie AI, Cojocneanu-Petric R, et al. Exosomes-Small Players, Big Sound. Bioconjug Chem 2018;29:635-48.

46. Clayton A, Court J, Navabi H, et al. Analysis of antigen presenting cell derived exosomes, based on immunomagnetic isolation and flow cytometry. J Immunol Methods 2001;247:163-74.

47. Carnell-Morris P, Tannetta D, Siupa A, et al. Analysis of Extracellular Vesicles Using Fluorescence Nanoparticle Tracking Analysis. Methods Mol Biol 2017;1660:153-73.

48. Anderson W, Lane R, Korbie D, et al. Observations of Tunable Resistive Pulse Sensing for Exosome Analysis: 
Improving System Sensitivity and Stability. Langmuir 2015;31:6577-87.

49. Liu JJ, Bratkowski MA, Liu X, et al. Visualization of distinct substrate-recruitment pathways in the yeast exosome by EM. Nat Struct Mol Biol 2014;21:95-102.

50. Keller S, Sanderson MP, Stoeck A, et al. Exosomes: from biogenesis and secretion to biological function. Immunol Lett 2006;107:102-8.

51. Buschow SI, van Balkom BW, Aalberts M, et al. MHC class II-associated proteins in B-cell exosomes and potential functional implications for exosome biogenesis. Immunol Cell Biol 2010;88:851-6.

52. Stoorvogel W, Kleijmeer MJ, Geuze HJ, et al. The biogenesis and functions of exosomes. Traffic 2002;3:321-30.

53. Baietti MF, Zhang Z, Mortier E, et al. Syndecan-synteninALIX regulates the biogenesis of exosomes. Nat Cell Biol 2012;14:677-85.

54. Kahlert C, Kalluri R. Exosomes in tumor microenvironment influence cancer progression and metastasis. J Mol Med (Berl) 2013;91:431-7.

55. Utsugi-Kobukai S, Fujimaki H, Hotta C, et al. MHC class I-mediated exogenous antigen presentation by exosomes secreted from immature and mature bone marrow derived dendritic cells. Immunol Lett 2003;89:125-31.

56. Clayton A, Turkes A, Dewitt S, et al. Adhesion and signaling by $\mathrm{B}$ cell-derived exosomes: the role of integrins. FASEB J 2004;18:977-9.

57. Rieu S, Géminard C, Rabesandratana H, et al. Exosomes released during reticulocyte maturation bind to fibronectin via integrin alpha4beta1. Eur J Biochem 2000;267:583-90.

58. Hao S, Bai O, Li F, et al. Mature dendritic cells pulsed with exosomes stimulate efficient cytotoxic T-lymphocyte responses and antitumour immunity. Immunology 2007;120:90-102.

59. Morelli AE, Larregina AT, Shufesky WJ, et al. Endocytosis, intracellular sorting, and processing of exosomes by dendritic cells. Blood 2004;104:3257-66.

60. Fitzner D, Schnaars M, van Rossum D, et al. Selective transfer of exosomes from oligodendrocytes to microglia by macropinocytosis. J Cell Sci 2011;124:447-58.

61. Feng D, Zhao WL, Ye YY, et al. Cellular internalization of exosomes occurs through phagocytosis. Traffic 2010;11:675-87.

62. Nanbo A, Kawanishi E, Yoshida R, et al. Exosomes derived from Epstein-Barr virus-infected cells are internalized via caveola-dependent endocytosis and promote phenotypic modulation in target cells. J Virol 2013;87:10334-47.
63. Svensson KJ, Christianson HC, Wittrup A, et al. Exosome uptake depends on ERK1/2-heat shock protein 27 signaling and lipid Raft-mediated endocytosis negatively regulated by caveolin-1. J Biol Chem 2013;288:17713-24.

64. Escrevente C, Keller S, Altevogt P, et al. Interaction and uptake of exosomes by ovarian cancer cells. BMC Cancer 2011;11:108.

65. Hoshino A, Costa-Silva B, Shen TL, et al. Tumour exosome integrins determine organotropic metastasis. Nature 2015;527:329-35.

66. Zhang Y, Hu YW, Zheng L, et al. Characteristics and Roles of Exosomes in Cardiovascular Disease. DNA Cell Biol 2017;36:202-11.

67. Jansen F, Li Q. Exosomes as Diagnostic Biomarkers in Cardiovascular Diseases. Adv Exp Med Biol 2017;998:6170.

68. Kanninen KM, Bister N, Koistinaho J, et al. Exosomes as new diagnostic tools in CNS diseases. Biochim Biophys Acta 2016;1862:403-10.

69. Fitts CA, Ji N, Li Y, et al. Exploiting Exosomes in Cancer Liquid Biopsies and Drug Delivery. Adv Healthc Mater 2019;8:e1801268.

70. Masyuk AI, Masyuk TV, Larusso NF. Exosomes in the pathogenesis, diagnostics and therapeutics of liver diseases. J Hepatol 2013;59:621-5.

71. Zhang W, Zhou X, Zhang H, et al. Extracellular vesicles in diagnosis and therapy of kidney diseases. Am J Physiol Renal Physiol 2016;311:F844-F851.

72. Alipoor SD, Mortaz E, Varahram M, et al. The Potential Biomarkers and Immunological Effects of Tumor-Derived Exosomes in Lung Cancer. Front Immunol 2018;9:819.

73. Zhou X, Xie F, Wang L, et al. The function and clinical application of extracellular vesicles in innate immune regulation. Cell Mol Immunol 2020;17:323-34.

74. Cai J, Han Y, Ren H, et al. Extracellular vesicle-mediated transfer of donor genomic DNA to recipient cells is a novel mechanism for genetic influence between cells. J Mol Cell Biol 2013;5:227-38.

75. Kahlert C, Melo SA, Protopopov A, et al. Identification of double-stranded genomic DNA spanning all chromosomes with mutated KRAS and p53 DNA in the serum exosomes of patients with pancreatic cancer. J Biol Chem 2014;289:3869-75.

76. Kalluri R, LeBleu VS. Discovery of Double-Stranded Genomic DNA in Circulating Exosomes. Cold Spring Harb Symp Quant Biol 2016;81:275-80.

77. Thakur BK, Zhang H, Becker A, et al. Double-stranded DNA in exosomes: a novel biomarker in cancer detection. 
Cell Res 2014;24:766-9.

78. Salehi M, Sharifi M. Exosomal miRNAs as novel cancer biomarkers: Challenges and opportunities. J Cell Physiol 2018;233:6370-80.

79. Thind A, Wilson C. Exosomal miRNAs as cancer biomarkers and therapeutic targets. J Extracell Vesicles 2016;5:31292.

80. Lian J, Lin SH, Ye Y, et al. Serum microRNAs as predictors of risk for non-muscle invasive bladder cancer. Oncotarget 2018;9:14895-908.

81. Hallal S, Azimi A, Wei H, et al. A Comprehensive Proteomic SWATH-MS Workflow for Profiling Blood Extracellular Vesicles: A New Avenue for Glioma Tumour Surveillance. Int J Mol Sci 2020;21:4754.

82. Halvaei S, Daryani S, Eslami-S Z, et al. Exosomes in Cancer Liquid Biopsy: A Focus on Breast Cancer. Mol Ther Nucleic Acids 2018;10:131-41.

83. Stevic I, Müller V, Weber K, et al. Specific microRNA signatures in exosomes of triple-negative and HER2positive breast cancer patients undergoing neoadjuvant therapy within the GeparSixto trial. BMC Med 2018;16:179.

84. Zhou X, Zhu W, Li H, et al. Diagnostic value of a plasma microRNA signature in gastric cancer: a microRNA expression analysis. Sci Rep 2015;5:11251.

85. Yosef I, Goren MG, Qimron U. Proteins and DNA elements essential for the CRISPR adaptation process in Escherichia coli. Nucleic Acids Res 2012;40:5569-76.

86. Cho E, Nam GH, Hong Y, et al. Comparison of exosomes and ferritin protein nanocages for the delivery of membrane protein therapeutics. J Control Release 2018;279:326-35.

87. György B, Hung ME, Breakefield XO, et al. Therapeutic applications of extracellular vesicles: clinical promise and open questions. Annu Rev Pharmacol Toxicol 2015;55:439-64.

88. Tian T, Zhang HX, He CP, et al. Surface functionalized exosomes as targeted drug delivery vehicles for cerebral ischemia therapy. Biomaterials 2018;150:137-49.

89. Rani S, Ryan AE, Griffin MD, et al. Mesenchymal Stem Cell-derived Extracellular Vesicles: Toward Cell-free Therapeutic Applications. Mol Ther 2015;23:812-23.

90. Zhang B, Yin Y, Lai RC, et al. Mesenchymal stem cells secrete immunologically active exosomes. Stem Cells Dev 2014;23:1233-44.

91. Lee C, Mitsialis SA, Aslam M, et al. Exosomes mediate the cytoprotective action of mesenchymal stromal cells on hypoxia-induced pulmonary hypertension. Circulation 2012;126:2601-11.

92. Kanazawa H, Fujimoto Y, Teratani T, et al. Bone MarrowDerived Mesenchymal Stem Cells Ameliorate Hepatic Ischemia Reperfusion Injury in a Rat Model. PLoS One 2011;6:e19195.

93. Lai RC, Arslan F, Lee MM, et al. Exosome secreted by MSC reduces myocardial ischemia/reperfusion injury. Stem Cell Res 2010;4:214-22.

94. Salomon C, Ryan J, Sobrevia L, et al. Exosomal Signaling during Hypoxia Mediates Microvascular Endothelial Cell Migration and Vasculogenesis. PLoS One 2013;8:e68451.

95. Chen J, Liu Z, Hong MM, et al. Proangiogenic compositions of microvesicles derived from human umbilical cord mesenchymal stem cells. PLoS One 2014;9:e115316.

96. Yang Y, Hong Y, Cho E, et al. Extracellular vesicles as a platform for membrane-associated therapeutic protein delivery. J Extracell Vesicles 2018;7:1440131.

97. Bunggulawa EJ, Wang W, Yin T, et al. Recent advancements in the use of exosomes as drug delivery systems. J Nanobiotechnology 2018;16:81.

98. Jan AT, Malik MA, Rahman S, et al. Perspective Insights of Exosomes in Neurodegenerative Diseases: A Critical Appraisal. Front Aging Neurosci 2017;9:317.

99. ClinicalTrials.gov [Accessed on 23.07.2020]. Available online: https://clinicaltrials.gov/ct2/results? cond=exosome $\mathrm{s} \&$ Search=Apply\&recrs=e\&age $\_\mathrm{v}=\& \mathrm{gnd} \mathrm{r}=\&$ type $=\& \mathrm{rslt}=$

100.Wang K, Jiang Z, Webster KA, et al. Enhanced Cardioprotection by Human Endometrium Mesenchymal Stem Cells Driven by Exosomal MicroRNA-21. Stem Cells Transl Med 2017;6:209-22.

101.Lou G, Chen Z, Zheng M, et al. Mesenchymal stem cellderived exosomes as a new therapeutic strategy for liver diseases. Exp Mol Med 2017;49:e346.

102. Kim HS, Choi DY, Yun SJ, et al. Proteomic analysis of microvesicles derived from human mesenchymal stem cells. J Proteome Res 2012;11:839-49.

103. Merino-González C, Zuñiga FA, Escudero C, et al. Mesenchymal Stem Cell-Derived Extracellular Vesicles Promote Angiogenesis: Potential Clinical Application. Front Physiol 2016;7:24.

104. Tracy SA, Ahmed A, Tigges JC, et al. A comparison of clinically relevant sources of mesenchymal stem cellderived exosomes: Bone marrow and amniotic fluid. J Pediatr Surg 2019;54:86-90.

105.Ha D, Yang N, Nadithe V. Exosomes as therapeutic drug 
carriers and delivery vehicles across biological membranes: current perspectives and future challenges. Acta Pharm Sin B 2016;6:287-96.

106. Di Rocco G, Baldari S, Toietta G. Towards Therapeutic Delivery of Extracellular Vesicles: Strategies for In Vivo Tracking and Biodistribution Analysis. Stem Cells Int 2016;2016:5029619.

107. Ren S, Chen J, Duscher D, et al. Microvesicles from human adipose stem cells promote wound healing by optimizing cellular functions via AKT and ERK signaling pathways. Stem Cell Res Ther 2019;10:47.

108.Zhang K, Yu L, Li FR, et al. Topical Application of Exosomes Derived from Human Umbilical Cord Mesenchymal Stem Cells in Combination with Sponge Spicules for Treatment of Photoaging. Int J Nanomedicine 2020;15:2859-72.

109. Ferreira ADF, Gomes DA. Stem Cell Extracellular Vesicles in Skin Repair. Bioengineering (Basel) 2018;6:4.

110.Sengupta V, Sengupta S, Lazo A, et al. Exosomes Derived from Bone Marrow Mesenchymal Stem Cells as Treatment for Severe COVID-19. Stem Cells Dev 2020;29:747-54.

111.Ilic N, Savic S, Siegel E, et al. Examination of the regulatory frameworks applicable to biologic drugs (including stem cells and their progeny) in Europe, the U.S., and Australia: Part II-A method of software documentary analysis. Stem Cells Transl Med 2012;1:909-20.

112.Ilic N, Savic S, Siegel E, et al. Examination of the regulatory frameworks applicable to biologic drugs (including stem cells and their progeny) in Europe, the U.S., and Australia: part I--a method of manual documentary analysis. Stem Cells Transl Med 2012;1:898-908.

113.European_Union. Volume 4 EU Guidelines for Good Manufacturing Practice for Medicinal Products for Human and Veterinary Use; Annex 2, Manufacture of Biological Active Substances and Medicinal Products for Human Use.

114. GMPguidelines. [assessed on 28 July 2020]. Available online: http://ec.europa.eu/health/documents/eudralex/ vol-4/index_en.htm

115. ClinicalTrialsGuidelines. [assessed on 28 July 2020]. Available online: http://ec.europa.eu/health/documents/ eudralex/vol-10/index_en.htm

116.EMA/CHMP/BWP/534898/2008. Guideline on the requirements for quality documentation concerning biological investigational medicinal products in clinical trials.
117.Lener T, Gimona M, Aigner L, et al. Applying extracellular vesicles based therapeutics in clinical trials an ISEV position paper. J Extracell Vesicles 2015;4:30087.

118.EMEA/CHMP/410869/2006. Guideline on human cellbased medicinal products.

119. Ruiss R, Jochum S, Mocikat R, et al. EBV-gp350 Confers B-Cell Tropism to Tailored Exosomes and Is a NeoAntigen in Normal and Malignant B Cells-A New Option for the Treatment of B-CLL. PLoS One 2011;6:e25294.

120.REGULATION/EC/1394/2007. Regulation on advanced therapy medicinal products.

121.EMA/CAT/CPWP/686637/2011. Guideline on the riskbased approach according to annex I, part IV of Directive 2001/83/EC applied to Advanced therapy medicinal products.

122. Kriebardis A, Antonelou M, Stamoulis K, et al. Cellderived microparticles in stored blood products: innocentbystanders or effective mediators of post-transfusion reactions? Blood Transfus 2012;10 Suppl 2:s25-s38.

123. Burke J, Kolhe R, Hunter M, et al. Stem Cell-Derived Exosomes: A Potential Alternative Therapeutic Agent in Orthopaedics. Stem Cells Int 2016;2016:5802529.

124.Zhang J, Guan J, Niu X, et al. Exosomes released from human induced pluripotent stem cells-derived MSCs facilitate cutaneous wound healing by promoting collagen synthesis and angiogenesis. J Transl Med 2015;13:49.

125. Devhare PB, Ray RB. A novel role of exosomes in the vaccination approach. Ann Transl Med 2017;5:23.

126. Nolte-'t Hoen E, Cremer T, Gallo RC, et al. Extracellular vesicles and viruses: Are they close relatives? Proc Natl Acad Sci U S A 2016;113:9155-61.

127.Joo HS, Suh JH, Lee HJ, et al. Current Knowledge and Future Perspectives on Mesenchymal Stem Cell-Derived Exosomes as a New Therapeutic Agent. Int J Mol Sci 2020;21:727.

128. Capricor Therapeutics. [assessed on 28 July 2020]. Available online: http://capricor.com/

129. Kimera Labs. [assessed on 28 July 2020]. Available online: https://kimeralabs.com/

130. Exosome Diagnostics. Personalized Precision Healthcare. [assessed on 28 July 2020]. Available online: http://www. exosomedx.com/

131. NanoSomiX Inc. [assessed on 28 July 2020]. Available online: http://www.nanosomix.com/technology

132. Evox Therapeutics. [assessed on 28 July 2020]. Available online: https://www.evoxtherapeutics.com/

133. Codiak Biosciences. Realizing the potential of exosome biology. [assessed on 28 July 2020]. Available online: 
http://www.codiakbio.com/\#cellular-communicators

134. ArunA Biomedical. [assessed on 28 July 2020]. Available online: https://www.arunabiomedical.com/

doi: $10.21037 /$ sci-2020-037

Cite this article as: Muthu S, Bapat A, Jain R, Jeyaraman N, Jeyaraman M. Exosomal therapy-a new frontier in regenerative medicine. Stem Cell Investig 2021;8:7. 135.de Couto G, Liu W, Tseliou E, et al. Macrophages mediate cardioprotective cellular postconditioning in acute myocardial infarction. J Clin Invest 2015;125:3147-62. 